\title{
EL PERSONAL LABORAL AL SERVICIO DE LA ADMINISTRACION Y LA LABORALIZACION DE LA FUNCION PUBLICA
}

\author{
por \\ Valentín Pérez Martínez \\ Colaborador del Departamento de Derecho Administrativo \\ de la Facultad de Derecho de la Universidad de Salamanca \\ Técnico de Administración Local
}

SUMARIO: I. PROBLEMATICA GENERAL.-II. DELIMITACION CONCEPTUAL DE LA FIGURA DEL TRABAJADOR AL SERVICIO DE LA ADMINISTRACION.-III. EL ACCESO A LA AD. MINISTRACION DEL PERSONAL LABORAL: EL REGIMEN LEGAL DE SU CONTRATACION.-IV. LA LABORALIZACION DE LA FUNCION PUBLICA Y LA CONSTITUCION DE 1978.V. A MODO DE CONCLUSION.

\section{PROBLEMATICA GENERAL}

Los estudios doctrinales sobre la función pública han puesto todo su empeño en analizar los problemas que afectan al personal que, prestando sus servicios en las diferentes Administraciones públicas, se rige por una relación de naturaleza estatutaria. La función pública es objeto de tratamiento multidisciplinario, siendo los enfoques muy diversos: unos utilizan la perspectiva jurídica, otros son de índole sociológica, e incluso se procede a su estudio centrando el interés en hipotéticas políticas de administración de personal, resultan en cambio mucho más ocasionales, entre todos ellos, aquellos que prestan su atención a ese importante colectivo que trabaja en 
la Administración ligado a la misma por una relación de naturaleza laboral. A este peculiar personal pretenden referirse las páginas que siguen, sin que ello sea óbice, antes bien parece necesario hacer una referencia comparativa a la situación y a la normativa legal que afecta a aquellos que en sentido estricto se denominan funcionarios públicos y que se ven afectados en la regulación de sus condiciones de empleo por un proceso de aproximación al régimen jurídico que regula el empleo privado y que en términos generales se conoce como laboralización de los funcionarios (1).

Desconocer la importancia de este colectivo laboral es un tremendo error que nos colocaría al margen de una realidad que subyace tanto a la sociedad en general como a la propia Administración de nuestro tiempo, lo que nos motiva a que sin sentirnos obligados a recurrir al Derecho comparado e intentando una aproximación a situaciones que nos son más cercanas, obviemos las connotaciones peyorativas respecto de los tradicionalmente llamados «obreros de la Administración», expresión inexacta e inaceptable hoy día, si se tiene en cuenta que la incorporación generalizada de profesionales al proceso productivo es un fenómeno social y económico que no ha dejado de afectar en gran medida a la propia Administración.

No es nuestra intención hacernos eco de la polémica terminológica existente sobre la procedencia o no de identificar a los funcionarios públicos como trabajadores de la Administración (2) pero

(1) El origen de este movimiento lo sitúa Tomás Ramón FeRnández en la evolución del aparato estatal que ha determinado el que grandes masas de funcionarios se encuentren en «una situación de proletarización y de disfavor con respecto a los trabajadores del sector privado, tanto en el plano económico, como en el político y sindical». Vid. La organización territorial del Estado y la Administración Pública en la nueva Constitución. Lecturas sobre la Constitución Española, vol. I, 1978, página 364 .

(2) Es conocida la tesis de GarRido Falla de clara oposición entre ambas figuras y que le lleva a afirmar que "el funcionario ante todo, es un funcionario y la dialéctica empresario-trabajador no tiene nada que ver con la dialéctica Administración-funcionario, al menos cuando se refiere a los altos niveles de la función pública” (vid Comentarios a la Constitución, 1985, pág. 1439), salvedad esta última de extrema importancia si se tiene en cuenta que el número de estos últimos es muy reducido, como ha puesto de relieve recientemente BAENA DEL ALCAZAR, vid. Estructura de la función pública y burocracia en España, IVAP, 1984. En la misma línea se encuentra Luis MARTíN REBollo que afirma con cierta ironía que «frente a algunas pretensiones un tanto ingenuas de cambios semánticos que a menudo se utilizan en el lenguaje sindical para designar a los «trabajadores de la Administración Pública», no está de más reivindicar el nombre original que expresa muy bien el contenido de su trabajo, una función pública, un servicio público, remunerado también con dinero público, es decir, de todos, y con el no desdeñable privilegio en los tiempos que corren de no tener que ser sometidos a ninguna 
el solo hecho de su existencia revela que un fenómeno profundo conmueve los cimientos de nuestra Administración, aquejada de forma crónica por un mal funcionamiento (3) a cuya solución, siquiera parcialmente, es indudable que han de contribuir las experiencias provenientes del ámbito empresarial privado. Se ha puesto de relieve la imposibilidad de establecer una separación radical entre émpleo público y trabajo privado (4), destacando tanto la influencia recíproca entre las esferas jurídicas laboral y administrativa como el trasvase de instituciones jurídicas nacidas en cada una de ellas, lo que explica la especial dificultad para encontrar un modelo normativo estable - que no estático- para unas relaciones que ocupan un espacio fronterizo entre ambos sectores del Derecho, sobre todo si se tiene en cuenta su carácter esencialmente dialéctico, puesto una vez más de manifiesto tras la crisis económica de los últimos años que ha obligado a reconsiderar la clásica configuración del empleo público.

Pero tan sólo recientemente comienza a dibujarse un sistema normativo que bien de forma específica o bien globalmente, en el conjunto de disposiciones reguladoras de la función pública tratan de configurar las relaciones existentes entre las Administraciones y el personal que en régimen de contratación laboral se vincula a las mismas.

La oportunidad que a este respecto supuso la reforma legislativa de 1963-1964 no constituyó en ningún momento una aprehensión general de carácter normativo de esta problemática. La anomia administrativa vendrá a significar una dejación absoluta a la legislación laboral, lo que en el terreno de los hechos se tradujo en un régimen disperso, que por la diversidad y multiplicidad de normas -Ordenanzas laborales y Convenios colectivos- referidas a actividades de similar cuando no idéntica naturaleza, han impedido cualquier homogeneidad que significase un tratamiento uniforme para un amplio sector de trabajadores que por las especiales connotaciones que tenía el sujeto empleador demandaban siquiera en parte una regulación específica. Hay que tener en cuenta que nos estamos refiriendo no ya a la vieja administración de policía, sino

medida de reconversiónn industrial», vid. «La función pública local de cara a su reforma», REVL, núm. 223, julio-septiembre 1984, pág. 235.

(3) Un panorama general actual sobre la Administración española aparece en la obra de Alejandro NIETO: La organización del desgobierno, 1984.

(4) Juan LOPEZ GANDfa: "Las relaciones colectivas en el empleo público y la Constitución Española», RDP, núm. 83, 1981, págs. 397-402. 
a una administración que debe desenvolverse en unas coordenadas sociales y económicas completamente nuevas, en el marco de lo que de forma general se conoce como Estado intervencionista (5).

Parece claro que las categorías que fueron válidas para un sistema económico estático, ya no servían para otro distinto caracterizado por un desenfrenado proceso de desarrollo que debería haberse tenido en cuenta por nuestro legislador. El desorbitado, pero sobre todo, rápido crecimiento de la Administración en España conlleva un amplio desarrollo del colectivo laboral en su seno (6). Si a esto unimos que la conflictividad de las relaciones laborales a partir de los años sesenta no resulta ajena a quienes bajo este régimen trabajan en la Administración y que la incorporación de sectores profesionales sometidos al fenómeno de la "salarización» no permiten continuar con los viejos esquemas normativos pensados para un sector laboral reducido, mayoritariamente de carácter manual y de escaso carácter reivindicativo, lo que justifica y permite comprender la urgencia de su regulación normativa.

A todo ello hay que unir la existencia de una discriminación intolerable, incompatible con los principios dibujados en nuestro ordenamiento constitucional, especialmente en el terreno retributivo, entre personas que desarrollaban funciones similares, por el solo hecho de no estar sometidas a un régimen administrativo, especialmente cuando no existía una real delimitación de funciones, mientras que sí se encontraban sometidos al sistema de restricciones innatas al conjunto de la función pública.

Todos estos factores ponen en cuestión la relación de empleo público tal y como se concebía con anterioridad a la Constitución de 1978, exigiendo la construcción de un nuevo sistema que concilie las necesidades organizativas de la Administración Pública de nuestros días, equipare las condiciones de trabajo de los funcionarios públicos y de los trabajadores a su servicio y permita para

(5) Utilizamos esta acepción en el mismo sentido que emplea Máximo Severo Giannini en Premisas sociológicas e históricas del Derecho Administrativo, 1980, página 67, esto es, como demanda de mayor protección social para asegurar su subsistencia por parte de las nuevas clases y grupos partícipes del poder.

(6) En un reciente estudio, vid. "Los problemas del personal no funcionarion, $R E V L$, núm. 225, enero-marzo 1985, pág. 147, GonZÁlez-HabA GuISADo, tomando como base los Presupuestos para 1984, evalúa el total del personal de las Administraciones Públicas en 1.477.208, de los cuales 176.601 serian contratados laborales. Hay que tener en cuenta que a pesar de incluir los funcionarios locales en el cómputo global no lo hace con los contratados laborales al servicio de esta Administración, lo que hace que dado su progresivo incremento en los últimos años habría que tomar con alguna reserva la evaluación anterior. 
los mismos un reconocimiento de los derechos públicos subjetivos reconocidos constitucionalmente y que reclama una normativa no restrictiva, en definitiva un sistema que explicite la tendencia detectada mucho antes de la implantación del nuevo régimen político por PaRAda VÁzQuez, según el cual «en el Derecho laboral se manifiesta por las aspiraciones, en alguna forma ya realidades, de estabilidad de empleo y seguridad social, viejas conquistas del funcionariado, y la tendencia de éste a la rotura del principio autoritario de fijación unilateral por el Estado de las condiciones de trabajo, lo que deriva no de una supremacía y superioridad económica, sino de una determinada concepción jurídica» (7).

\section{DELIMITACION CONCEPTUAL DE LA FIGURA DEL TRABAJADOR AL SERVICIO DE LA ADMINISTRACION}

Una primera aproximación al problema objeto de estudio nos obliga a precisar la caracterización de la Administración Pública como sujeto empleador o por decirlo en otros términos, como empresario. Cualidad ésta admitida sin exclusión tanto por el conjunto de disposiciones legales en la materia como por la propia doctrina y jurisprudencia al respecto (8) y que, sin embargo, exige concretarla en cuanto a su incidencia en el ámbito de la Administración Pública en sentido estricto, omitiendo la referencia a las relaciones con personas cuyas actividades se efectúan en el seno de los organismos paraestatales o servicios administrativos descentralizados o en el ámbito local por medio de los servicios municipalizados o provincializados. Hecha esta primera aclaración, hay

(7) José Ramón Parada Vazquez: Sindicatos y asociaciones de funcionarios públicos, 1968, págs. 26-27.

(8) La LCT de 1944, en su artículo 5, establecía tanto para el Estado como para Diputaciones y Ayuntamientos, su equiparación a los empresarios privados respecto de las obras o servicios públicos que se ejecuten directamente o por administración, lo que a juicio de Alonso OleA no significaba que se tratase de que quedaran equiparadas sino que se trataba de auténticos empresarios. En el artículo 1.1 de la LPL de 1973 así les consideraba urespecto de los trabajadores que tengan a su servicio, ya sea directamente o a través de organismos dependientes de ellosn, e idéntica interpretación cabía hacer del contenido del artículo 2.a) en conexión con el artículo 1.1. en los artículos 3.a) y artículo 1 del Estatuto de los Trabajadores aprobado por Ley de 10 de marzo de 1980 . Asimismo, la doctrina se refiere a la Administración como sujeto empresarial, en este sentido y entre otros BAYóN-Pérez BotiJa: Manual de Derecho del Trabajo, vol. I, 10." ed., págs. 245-246, y Alonso Olea: Derecho del Trabajo, 3." ed., págs. $29-31$ y 75 , en las que transcribe la doctrina jurisprudencial al respecto y a las que nos remitimos. 
que afirmar que prescindiendo de la naturaleza del servicio o de las circunstancias políticas o administrativas que inducen a las administraciones a la realización de contrataciones sometidas al régimen prescrito por el Derecho del Trabajo, y obviando por tanto las razones de organización que conducen a la misma (9), el hecho cierto es que existe un conjunto de personas que establecen con la Administración Pública relaciones de trabajo por su cuenta y bajo dependencia de la misma a cambio de una determinada retribución y cuyo status corresponde al de los trabajadores sometidos al régimen jurídico laboral en idénticas circunstancias al personal encuadrado en las empresas privadas, incluso cuando éstas prestan los mismos servicios, por lo que establecer diferenciaciones en estas circunstancias, implicaría en opinión de PÉrEz BotiJa el que pudiesen originar hasta "una competencia desleal por posibles desigualdades de trato" (10).

Así pues, y como señala la jurisprudencia del Tribunal Supremo, S. de 9-2-1970 (R. 651), la Administración Pública —en el supuesto en cuestión, un Ayuntamiento-, para el cumplimiento de sus fines puede actuar «de dos distintas formas: a) Como entidad de derecho público, a través de sus organizados servicios municipales integrados por elementos de tipo real y personal y estos últimos como funcionarios o empleados de los mismos con vinculación jurídicoadministrativa, y b) como empresa privada, contratando al personal asalariado necesario para realizar un determinado cometido y por tanto según sea la relación que ligue a dichas Corporaciones con su personal, administrativa o laboral, así serán competentes las jurisdicciones de una u otra índole para conocer y decidir los litigios que en las mismas se susciten" (11).

No es posible pensar que de la naturaleza de la actividad de las personas insertas en un ente administrativo pueda inferirse un

(9) Precisamente el Consejo de Estado, en un dictamen de 14 de diciembre de 1960, establece que el hecho de que los diferentes grupos y categorías de personal al servicio de la Administración se sometan a un régimen administrativo o laboral se reduce a meras técnicas de organización que pueden ser utilizadas indistintamente. Es indudable que en último extremo, el criterio que debe guiar el método o forma de organización elegido no debe ser otro que el de obtener una mayor eficiencia en el servicio a prestar.

(10) Eugenio Pérez BotiJa: «El problema de los "no funcionarios" en las entidades públicas", incluido en Estudios dedicados al profesor Gascón y Marín, 1952, en nota a pie de pág. núm. 5, pág. 130.

(11) En este mismo sentido se pronuncia en SS de 13-6-1967 (R. 2.319) y 18-11-1967 (R. 4.438). 
criterio definidor de las mismas (12). En este sentido, las referencias sociológicas se hacen ineludibles y así, la distinta valoración social que nos merecen las diferentes profesiones y oficios, no se corresponden con las de tiempos pretéritos en los que la disyuntiva entre actividad burocrática versus actividad industrial o trabajo intelectual frente a trabajo manual eran acordes con una sociedad rígidamente estatificada y con un modelo de producción en ciernes que no había contemplado aún el formidable desarrollo de nuestros días y la compleja trama de actividades profesionales que conlleva. Basta con dar un somero repaso a las páginas del $B O E$, sobre todo últimamente, para poder apreciar cómo las administraciones ofrecen la inserción en sus cuadros laborales a personas a las que se exige alta cualificación informática o de las que se demanda el asesoramiento jurídico o económico o se incluye entre los requisitos la previa detentación de un título en ingeniería, por citar tan sólo estos ejemplos, mientras que a contrario, cualquier peón de vías y obras puede reunir todos los requisitos para formar parte de una plantilla administrativa, percibir sus retribuciones en base a un presupuesto público y en definitiva estar sometido al régimen estatutario en su condición de funcionario público. Parece claro, pues, que generalmente no es la naturaleza de la actividad, sino criterios de carácter organizatorio, que tienen un claro sustrato político, los que constituyen la razón primordial del carácter laboral para las personas que se someten a este régimen jurídico. En definitiva, aunque el origen de estas relaciones especiales hay que buscarlo en un puro acto de poder administrativo, esto no excluye que tanto las condiciones de trabajo como las repercusiones económicas consiguientes sean consecuencia de un nexo contractual de carácter laboral que interesa a los propios detentadores del poder político intentando obviar así la rigidez del sistema estatutario.

En conclusión, y como ha dicho MEDINA ORTEGa refiriéndose a la Administración central "para aplicar al empleado la legislación laboral, será necesario que exista norma terminante y expresa que diga que es legalmente trabajador, y que sus relaciones con el

(12) E. Pérez Botija: El problema..., págs. 142 y 143. Para este autor la idea de una actividad que no quepa insertar en el cuadro de las funciones públicas, es decir, de los servicios prestados corrientemente por los funcionarios, podrá valernos como elemento fundamental de referencia, aunque no acepta este criterio de manera absoluta y advierte de la imposibilidad de diferenciar el trabajo administrativo y el de ejecución, por lo que la índole del trabajo apuede servir en cierto modo para facilitar determinadas exclusiones». 
Estado son las propias de un contrato de trabajo" (13) o bien que establezca que han de regirse por Ordenanzas laborales o Convenios colectivos. En este sentido, una primera dificultad surge al no haber existido uniformidad en la terminología con que se designa al per. sonal que ve reguladas sus relaciones con la Administración por la legislación laboral (14), así mientras en la Administración Central se designa como «trabajadores al servicio de la Administración civil» (art. 7.1..$^{\circ}$ LFCE), respecto de los Organismos autónomos la LEEA (arts. 79 y 83) los designa como «obreros» y en el ámbito local se trataría del "personal para la realización de funciones manuales concretas» (art. 25.2 RD 3046/1977, de 6 de octubre). A pesar de las diversas denominaciones, de ellas pueden extraerse dos notas definitorias: de una parte, todas apuntan al desarrollo de funciones de carácter fundamentalmente manual - sin concretar-, por lo que las de índole burocrático corresponderían a los funcionarios en cualquiera de las clases previstas en la legislación, y de otra, estamos ante un colectivo que desarrolla unas funciones con carácter temporal, aunque más que al hecho en sí de la mayor o menor duración de sus relaciones laborales con la Administración, como se deriva del carácter fijo con que vienen desempeñándose, se apunta a un intento de diferenciación de los funcionarios, caracterizados por la permanencia y la inamovilidad en el empleo.

A pesar de la imprecisión legislativa que ha determinado la falta de unidad conceptual (15), puede avanzarse hacia la misma merced a la labor jurisprudencial que viene considerando de forma reiterada la existencia de un nexo contractual de naturaleza laboral partiendo de la negación de la cualidad de funcionario, lo que vendría determinado por la no existencia de nombramiento, el desempeño de funciones que no son «exclusivas ni peculiares" de la

(13) Manuel Medina ORTEGa: «El personal contratado en la Administración local”, $R E V L$, núm. 115, enero-febrero 1961, pág. 6.

(14) En Francia, a partir de WaLINE, se impone la denominación de agentes públicos para referirse al personal contratado--Una clasificación completa referida a estos aagents publics» puede encontrarse en el libro de M. Piouemal: Le fonctionnaire. Droits et garanties, 1973, págs. 60-70.

(15) Antonio RODRfguez Molero: «Trabajadores al servicio de la Administración Local», RISS, año XIV, núm. 5, 1965, pág. 942, se hace eco de tal imprecisión respecto del concepto de obrero y la dificultad de su distinción con el empleado, así como el inacabado concepto de funcionarios públicos, lo que a su juicio hace «sumamente difícil la tarea jurisprudencial en los múltiples casos concretos en que tuvo que pronunciarse sobre estos extremos». A tales dificultades cabría añadir otra suplementaria derivada de la contraposición entre aobrero-funcionario" y obrero que no es funcionario que carece de sustancia distintiva y que se establece con el único fin de aplicarles un régimen legal distinto. 
Administración a la que se vinculan o bien sus servicios manuales no tienen la trascendencia de servicio público, la no inclusión en plantilla y la no percepción de sus retribuciones en base a la exis. tencia de una partida presupuestaria determinada sino que son antes bien partidas únicas y exclusivas (16) y es partiendo de la concurrencia de estas notas definitorias en sentido negativo que puede hablarse de la existencia de un contrato en régimen laboral, independientemente de la denominación que los interesados le atri. buyan (S. de 5-12-1980, R. 4.865).

En definitiva, tan solo la cualificación como funcionario como mantiene García Trevijano (17), diferencia a éste del obrero, otro problema distinto es entrar en las diferencias entre ambas figuras jurídicas respecto a temas tan dispares como el tipo de trabajo, el modo de retribución o la forma de admisión. No es de extrañar, por tanto, que ante esta indefinición las organizaciones sindicales más representativas en este colectivo de trabajadores lograsen incluir entre las cláusulas del Acuerdo Marco para el personal laboral de la Administración Civil del Estado y sus Organismos Autónomos (18) la necesidad de describir «de manera clara y precisa las tareas y funciones que correspondan a cada categoría profesional», problema éste el de la clasificación profesional, por otra parte común al conjunto de la función pública como habíamos adelantado de forma implícita. Habrá que coincidir con Alonso Olea, a la vista de lo expuesto que no existen diferencias de fondo entre las relaciones que se dan entre empresarios y trabajadores y los que existen entre el personal trabajador al servicio de la Administración y ésta, es más, para el citado autor «los únicos funcionarios claramente distinguibles son los que ostentan los altos poderes del Estado" (19) o lo que es lo mismo, lo que un amplio sector doctrinal califica como funcionarios que ostentan la posibilidad de ejercer la autoridad.

La diferente naturaleza jurídica respecto al funcionario some-

(16) Vid. entre otras, Sentencias del Tribunal Supremo de 6-12-1980 (R. 4.866), 26-2-1981 (R. 1.284), 45-1981 (R. 2.059) y 19-9-1981 (R. 3.429).

(17) José A. García-Trevijano: «Relación orgánica y relación de servicio en los funcionarios públicos», RAP, núm. 13, 1954, pág. 68.

(18) Publicado en el $B O E$ núm. 168 (15-7-1982), mediante resolución de la DGT de 1-7-1982, justificando en su Preámbulo la forma de Acuerdo Marco como único instrumento jurídico adecuado ante ula imposibilidad legal actual de dictar una norma reglamentaria que regule las condiciones de trabajo del personal laboral de la Administración".

(19) M. Alonso Olea: Derecho del Trabajo, pág. 30. 
tido en su relación de empleo al Derecho Administrativo, ha sido sancionada por el propio Tribunal Constitucional en S. de 27-7-1982 que resolvió un recurso contra el Decreto del Gobierno Vasco sobre la regulación colectiva de las condiciones de trabajo en la Administración Local, que disponía aplicables sus normas "a todas las personas físicas vinculadas a las predichas Corporaciones Locales por relaciones de servicios profesionales retribuidos, cualquiera que sea la naturaleza jurídica de dichas relaciones». Frente al mismo, el Tribunal Constitucional establece de forma tajante en la fundamentación jurídica de la sentencia que «de la legislación vigente ni es posible racionalmente inducir un principio básico que no sea el del tratamiento no unitario por diferenciado entre funcionarios públicos y personal laboral al servicio de las Corporaciones Locales".

No obstante este pronunciamiento, la brecha queda abierta porque diferenciar al trabajador del funcionario siguiendo la noción del régimen es una forma de huir del problema como acertadamente señala BooUERA (20) y posiblemente se apreciaría tangiblemente la redundancia entre normas administrativas y normas laborales al tratar de explicar el contenido de ambas.

A este reto va a responder la Ley de Medidas para la Reforma de la Función Pública que incluye en su ámbito de aplicación a todo el personal al servicio de la Administración, estableciendo disposiciones concretas para el personal laboral en aquellas materias que por su especificidad así lo exigen, pero que viene a responder a una fuerte demanda social de aproximación entre el funcionario y el trabajador (21), e incluso hace prevalecer este último status, concretamente al referirse en su artículo 15.1 a las relaciones de puestos de trabajo, puesto que se debe especificar en ellas «aquellos puestos que, en atención a la naturaleza de su contenido, se reservan a funcionarios públicos», lo que hace presumir que va a haber un incremento en cantidad y en entidad de los puestos reservados al personal laboral, frente a los funcionarios públicos que habrán de ocupar tan sólo aquellos que se les reserven, prescripción ésta que, a juicio de GARRIDO FALla cabría imputar posible inconstituciona-

(20) José María Boouera Oliver: Derecho Administratipo, vol. I, 1979, pág. 247.

(21) Vicente GoNZALEZ-HaBA, en Certamen, Revista de Administración Local, número 490, enero 1984, págs. 24 y 25, se refiere a esta aproximación en dicha Ley al hablar de promoción privada en lugar de carrera administrativa, seguridad social en vez de derechos pasivos e incorporar del mundo laboral la regulación del régimen de permisos, el complemento de productividad como concepto retributivo, etc. 
lidad por entender que «está literalmente invirtiendo el principio del artículo 103.3, al convertir en excepción lo que necesariamente y por mandato constitucional debe ser la regla» (22), entendiendo que se está abriendo una vía para los que denomina funcionarios políticos o personas de especial confianza que podrían pasar a ocupar determinados puestos que serían "usurpados» a los funcionarios públicos.

\section{EL ACCESO A LA ADMINISTRACION DEL PERSONAL LABORAL: EL REGIMEN LEGAL DE SU CONTRATACION}

La excesiva rigidez con que se ha interpretado el régimen legal en materia de funcionarios, ha generado un movimiento de reacción de tendencia contraria a favor de lo que el TS en S. de 10-5-1982 (R. 3.159) ha denominado Administración por contrato (government by contract), que este Alto Tribunal entiende "que si no constituye una fórmula ideal o perfecta, sí que sirve para corregir algunos de los excesos inherentes al régimen funcionarial de carrera, con la concepción patrimonialista y vitalicia que éste provoca".

Esta doctrina del Tribunal Supremo de signo evidentemente progresista, está avalada por las propias necesidades administrativas -especialmente de los entes locales- que intentan eludir un sistema en teoría más perfecto, pero que no siempre se adapta a las posibilidades económicas de un ente público para cubrir los servicios públicos que les son propios.

Vamos, pues, a referirnos en concreto al problema relativo a las condiciones de acceso al empleo de la Administración de los trabajadores contratados en régimen laboral. Es indudable que el Estado de Derecho sancionado por nuestra máxima Ley exige la existencia de normas jurídicas que establezcan un procedimiento público y objetivo, basado en el principio de igualdad (art. 23.2) y bajo la tutela de los principios del mérito y capacidad (art. 103.3), pero junto a esta realidad hay otra que incide directamente sobre el problema de su acceso y que no es otra que la vertebración autonómica del Estado español que no ha dejado de plantear problemas específicos respecto del personal que accede a las Comunidades Autónomas en régimen laboral (23).

(22) F. Garrido Falla: Reformas de la Función Pública, 1985, pág. 76.

(23) Por un RD de 22 de junio de 1983 por el que se dictan normas para faci- 
No hay que olvidar tampoco que tradicionalmente estos sistemas de contratación en la Administración han adolecido de graves deficiencias derivadas de la arbitrariedad con que se produce el ingreso, producto de vicios y corruptelas como el «amiguismo» y el "clientelismo" político, lo que no deja de generar problemas de eficacia al no existir una adaptación entre los puestos a cubrir y las necesidades reales planteadas y que por consiguiente ocasiona el que los propios contratados sean las víctimas más directas de estos sistemas, al verse privados de estabilidad, mermarse sus derechos laborales y ser discriminados en el aspecto retributivo (24).

Se pueden distinguir dos frases cronológicas en el reciente desarrollo constitucional en la materia y que vienen a coincidir claramente con las opciones ideológicas diferenciadas de los respectivos partidos gobernantes. Así, el proyecto de Ley Orgánica del Gobierno, de la Administración del Estado y de la Función Pública (25) hacía un pronunciamiento ambiguo en su artículo 48 al remitir las bases generales y las condiciones de empleo del personal laboral a los principios existentes sobre relaciones laborales, atendiendo en todo caso a "las peculiaridades del servicio público». No mucho más explícito resultaba el artículo 15 del proyecto de Ley que aprobaba las bases del Régimen Estatutario de los funcionarios públicos (26) que se limita a reproducir el mandato constitucional, exigiendo que «la contratación del personal laboral se efectuará mediante anuncio público y a través de pruebas que garanticen el mérito y capacidad de los aspirantes", pero ninguno de ambos proyectos llegarían a convertirse en norma legal y las condiciones

litar el traslado de personal a las Comunidades Autónomas respecto de los servicios transferidos por el Estado, se permite al personal en régimen de contratación laboral participar en las convocatorias para cubrir puestos de trabajo incluidos en las ofertas públicas de empleo, y en el supuesto de obtener destino use le aplicarán por analogía las normas que en este Decreto se establecen para el personal funcionario quedando la Comunidad Autónoma respectiva subrogada en los contratos que en su momento otorgó el Departamento u Organismo Autónomo de origen, así como en sus obligaciones de Seguridad Social y cualesquiera otras de carácter análogo» (art. 5.०.3).

(24) Estos defectos fueron denunciados en el I Congreso Federal de la FETAP en cuyas resoluciones, págs. 12-13, se aboga por un sistema alternativo basado en pruebas públicas en las que se atienda tanto a las necesidades que conllevan los puestos de trabajo que se cubran como a la preparación previa que se exige para tener acceso a las pruebas, fijándose en cualquier caso controles objetivos acordes con tales criterios.

(25) BO de las Cortes Generales, Congreso de los Diputados, núm. 109-1, de 5 de febrero de 1980.

(26) BO de las Cortes Generales, Congreso de los Diputados, núm. 214I, de 9 de octubre de 1981. 
de acceso habrán de regirse por el Acuerdo Marco para este personal al que ya hemos hecho referencia.

El sistema que en el Acuerdo Marco se configura, toma como base la existencia del escalafón, en el que se han de contener las vacantes a cubrir, exigiendo que se realice por un procedimiento reglado y respetando el principio de publicidad. A partir de aquí, prioriza los concursos de traslado «entre los trabajadores fijos que ostenten la misma categoría profesional que corresponda a la vacante», en segundo lugar establece un sistema de ascensos mediante pruebas selectivas restringidas y por último permite el nuevo ingreso a través de pruebas selectivas libres. En cualquier caso, los contratos de trabajo que se realicen, en cuanto a su forma, deberán realizarse por escrito.

A este primer Acuerdo Marco seguirá otro de 24 de febrero de 1984 (27) en el que se van a introducir modificaciones significativas. En este orden, se va a hacer referencia a los principios de publicidad, igualdad, mérito y capacidad que han de presidir la selección y contratación de este personal. Seguirá hablándose de la provisión de vacantes mediante turnos de ascenso, traslado y libre, pero ya no se establecen prioridades sino que se deja su determinación a los futuros convenios colectivos que se negocien «atendiendo a las características del servicio y de los puestos a cubrir".

Resulta significativo cómo se establecen unos criterios generales bajo los que deberían producirse la provisión de vacantes, y entre ellos merece la pena destacarse los siguientes:

1) Niega valor a la antigüedad, impidiendo los ascensos por el mero transcurso del tiempo de servicios.

2) Establece como factor a tener en cuenta los méritos profesionales según baremos previamente establecidos, y

3) Impide la introducción de cláusulas discriminatorias en los convenios colectivos «en favor de familiares de los trabajadores o de cualquier otro tipo», como lógica consecuencia del principio de igualdad.

Será en la LMRFP de 2 de agosto de 1984 cuando se aborde por vez primera de forma conjunta el problema de acceso al puesto de trabajo tanto por funcionarios como por contratados laborales, revistiendo la selección de estos últimos de las mismas garantías que

(27) Publicado en el BOE núm. 55 (5-3-1984) mediante resolución de la DGT de 24 de febrero de 1984 . 
aquéllos, en consonancia con la identidad del sector en el que van a desarrollar su vida profesional, y dentro del proceso que hemos denominado de laboralización de la función pública.

Otra noción novedosa de esta Ley es la de oferta de empleo público, consistente en el conjunto de plazas dotadas presupuestariamente, que hallándose vacantes, no puedan ser cubiertas con los efectivos de personal existentes. Sobre esta idea se hará girar la selección del personal de las distintas administraciones, independientemente de que exista naturaleza funcionarial o estatutaria o no.

El artículo 19 LMRFP determina la necesidad de dar publicidad a la convocatoria y establece como sistemas de contratación: el concurso, la oposición o el concurso-oposición libre, siempre salvaguardando los principios de igualdad, mérito y capacidad, y acentuando -en aras a conseguir una mayor eficacia en la acción administrativa- la necesidad de conectar las pruebas exigidas en la selección con el puesto de trabajo a desempeñar.

La citada norma legal ha sido desarrollada por el Reglamento General de Ingreso del Personal al Servicio de la Administración del Estado, aprobado por un Real Decreto de 19 de diciembre de 1984, en el que se introduce una división en el conjunto del personal laboral, entre los que desempeñan su puesto de trabajo con carácter fijo y los que se consideran contratados con una duración determinada "para la realización de trabajos que no puedan ser atendidos por personal laboral fijo". La temporalidad deja de ser un criterio definitorio en sí mismo para el personal laboral, y entra en juego en relación con las necesidades y el tipo de actividad que motivan la contratación, y aunque se establece un régimen de selección diferenciado, en ambos casos la competencia para realizar las convocatorias es atribuida a los respectivos Departamentos ministeriales en los que se adscriban los puestos de trabajo a cubrir.

Para el personal fijo se establece como sistema general de selección el concurso, estableciendo los otros dos sistemas cuando así lo exijan "la naturaleza de las tareas a realizar», lo que no deja de ser contradictorio si se tiene en cuenta que ya de por sí este personal está llamado a realizar tareas específicas, y puede significar una puerta abierta a las arbitrariedades, ya que deja las manos libres a los órganos que han de ejecutar la contratación de este personal, pudiendo hacer prevalecer los criterios de clientelismo y amiguismo a que hicimos referencia, o lo que es mucho más peligroso, pueden encubrirse bajo contratos laborales, funciones reser- 
vadas a funcionarios, para los cuales, por contrario, se les conmina a ingresar en la Administración con carácter general a través del sistema de oposiciones.

Se establece una excepción para el supuesto de promoción interna o de cobertura de vacantes del personal laboral que no es de nuevo ingreso, en estos casos, la selección se efectúa bajo el imperio de las respectivas Reglamentaciones o por los convenios colectivos que estuvieran vigentes.

Resulta deliberadamente imprecisa la referencia a los órganos de selección, los cuales se constituirán expresamente para cada convocatoria, sin aludir a su composición y al número de integrantes, que en cualquier caso ha de ser impar, exigiendo de forma indeterminada que uno "al menos» tendrá que ser designado por los representantes de los trabajadores, sin concretar a estos efectos quién ni de qué forma debe determinarse esta cualidad.

La competencia en relación con el personal sujetó a Derecho laboral viene atribuida con carácter general -art. 12 del RD de 28 de noviembre de 1984 - al Ministerio de la Presidencia que, en concreto, propondrá al Gobierno la aprobación de la oferta de empleo público y las medidas encaminadas a la racionalización de plantillas, estableciendo los criterios generales para su selección y determinando qué puestos de trabajo corresponde desempeñar a este personal del conjunto incluido en las relaciones de puestos de trabajo. Esta unidad competencial hay que aceptarla con reservas si se tiene en cuenta la tradicional influencia del Ministerio de Economía y Hacienda con las limitaciones que se derivan del hecho de poder proponer las directrices a que deberán ajustarse los gastos de personal de la Administración del Estado.

Por lo demás habrá que tener en cuenta que la supresión del régimen de contratación administrativa que con carácter radical ha establecido la Ley de Medidas hace pensar, aunque ésta no lo diga de forma expresa, que en adelante la contratación de personal por parte de la Administración deberá adaptarse a lo dispuesto con carácter general en el Estatuto de los Trabajadores y sus normas complementarias (28).

En el ámbito de la legislación autonómica, cabe referirse a la Ley de 23 de julio de 1985 de la Función Pública de la Administración de la Generalidad catalana, en la que se considera personal

(28) V. GonzÁlez-Haba: Los problemas..., pág. 155. 
laboral a aquellas personas que ocupen puestos de trabajo clasificados como tales, para lo que se exige previa formalización por escrito del contrato de naturaleza laboral. Parece referirse con ello al personal que adquiere la condición de fijos, ya que recoge un supuesto excepcional —casos de urgencia o tareas de carácter temporal- de contratación laboral de carácter no permanente, lo que no puede entenderse como escalón previo al acceso como personal funcionario o contratado laboral con carácter permanente, puesto que los servicios prestados en dichas condiciones no constituyen en ningún caso mérito preferente, según señala el artículo 9 de aquella Ley.

Extraordinariamente significativa resulta la alusión hecha en el Preámbulo de la Ley de la Función Pública valenciana de 31 de julio de 1985 a la conveniencia de asimilar «el contenido de las relaciones laborales más ventajosas obtenidas por los trabajadores en sus años de lucha por el prógreso social y nada se opone, tam. poco, a que las normas de eficacia y las técnicas en boga en las empresas privadas constituyan normas de actuación y de obligado cumplimiento de las Administraciones públicas, en un sentido social progresista", en base a tal declaración de intenciones, rechaza la configuración de un modelo de función pública portador de esquemas jurídicos que no responden a su propia experiencia autonómica, reclamándose como nota definitoria de la regulación legal para esta Comunidad la tendencia a una función pública única.

Esta Ley, a nuestro modo de ver, ofrece una definición del personal laboral jurídicamente, si no más correcta, sí más completa que en el caso catalán, refiriendo a aquel "que ocupe puestos de trabajo clasificados de tal naturaleza en las plantillas y haya sido contratado conforme a la legislación laboral y en cualquiera de las modalidades de contratación que ésta prevea, o haya sido transferida por el Estado con tal carácter» (art. 7.1).

El espíritu de esta Ley responde al principio de otorgar unos mismos derechos a aquellas personas que realizan un mismo trabajo, evitando las disfunciones derivadas de la aplicación de regímenes jurídicos distintos. Se va a intentar, pues, evitar los conflictos padecidos en el período preautonómico e incluso al comienzo de la autonomía plena, producto del sometimiento a personas con las mismas funciones y actividades de regímenes jurídicos y retribuciones diferentes, para ello, otorga un status fijo a aquellas personas que sometidos en virtud de un contrato y del convenio apli- 
cable al régimen laboral realizaban funciones o actividades administrativas, permtiendo su incorporación a la función pública, previa la superación de cursos y pruebas de adaptación, si bien dándoles la opción - disposición transitoria 3 . $^{\text {- }}$ - a permanecer en una, cuanto menos extraña «situación de personal a extinguir» en los puestos que ocupen en ese momento. Mucho nos tememos que una vez más y por esta vía de las disposiciones transitorias se burlarán los principios constitucionales que operan respecto del acceso a la función pública, y lo que es peor habrá que calificar de abstracta la prohibición señalada al persona laboral de ocupar puestos de trabajo "clasificados exclusivamente para funcionarios", siendo propios del personal laboral los "puestos de trabajo de oficio, subalternos o que supongan el ejercicio de tareas manuales» (art. 16.5), en clara contradicción con la tendencia proclamada a la generalización de las contrataciones laborales, independientemente de la naturaleza de la actividad de las mismas.

La selección de personal se hace responder a los mismos criterios establecidos para los funcionarios y a los marcados por la legislación estatal, fijándose un período de prueba cuya determinación se deja al desarrollo reglamentario que tenga lugar, correspondiendo efectuar, o autorizar en su caso, su contratación al Conseller de Administración Pública.

Quizás sea en el ámbito administrativo local donde podamos encontrar una atención más pormenorizada respecto de la contratación del personal laboral. La competencia para su nombramiento venía siendo atribuida al Alcalde por el viejo texto de la LRL de 1955, competencia que se verá limitada a raíz de la Ley 40/1981, tan sólo por lo que respecta a la necesidad de obtener una previa autorización, abstracta por otra parte, del Pleno de la Corporación, pero tras esta habilitación, seguirá siendo el Alcalde quien lleve a cabo la ejecución en concreto (29). El citado RD 3046/1977, tan sólo refería que estos contratos serían de carácter temporal, pero sin limitar el plazo de su duración, por lo que venía a dejarse a las normas del Estatuto de los Trabajadores el régimen de esta contratación, fun-

(29) Enrique FAGES SEgURA: «Sobre contratación de personal», CUNAL, número 457, enero 1983, pág. 14, opina que «no parece lógico conceder al Pleno, en cuanto a la relación laboral, mayor intervención que la que tiene asignada en cuanto a la relación funcionarial, cuyo contenido y trascendencia son bastante más importantes desde el punto de vista juridico administrativo, sin omitir su mayor implicación económica en una gestión pública normals, particularidades éstas a las que el autor añade las necesidades derivadas del carácter contingente que caracteriza a la contratación laboral. 
damentalmente en sus artículos 8 , respecto de la forma -escrita si excede cuatro semanas en los contratos por tiempo determinado, presumiéndose realizado por tiempo indefinido en caso contrarioy 12 en cuanto a determinados requisitos relativos a la solicitud y clasificación profesional.

Es indudable que las Corporaciones Locales han tratado de eludir esta limitación temporal, intentando soslayar los requisitos legales exigidos para alcanzar la situación estatutaria, lo que ha dado pie a que el Tribunal Supremo se pronuncie al respecto, así mediante S. de 13 de julio de 1983 (R. 4.047) ha manifestado que «en el supuesto que se enjuicia, al versar sobre el acuerdo del Ayuntamiento de Arrigorriaga de contratar con carácter fijo a unos operarios contratados anteriormente por un año, se establece un régimen funcionarial que discrepa totalmente del que regulaba el D. de 6 de octubre de 1977 cuyo artículo 103 determina la forma de acceso de los funcionarios que realicen actividades de carácter predominantemente manual, que es por oposición o concursooposición, lo cual implica una discriminación orgánica respecto de los demás funcionarios en los otros Ayuntamientos del Estado».

Sin embargo, el carácter de relativa fijeza en el empleo que la legislación laboral concede con carácter general a los trabajadores ha sido subrayado por el propio Tribunal Supremo, que en S. de 10 de febrero de 1981 (R. 651) ha mantenido la continuidad de la relación laboral del personal contratado originariamente por una Corporación local cuya actividad pasa a prestarse a través de una empresa concesionaria, "pues este personal seguía realizando las mismas labores, en el mismo servicio público y percibiendo sus retribuciones de la misma fuente, aunque fuera por mediación, ahora, de una personalidad jurídica interpuesta, que en este sentido resultaba mera gestora de los intereses municipales".

La normativa local ha suscitado críticas al estimarse que permitía a las Corporaciones Locales "seguir contratando directamente sin procedimiento alguno de selección, casi con mayor liberalidad que antes, con la única cortapisa de la limitación temporal» (30), quizás por ello la nueva LRL de 2 de abril de 1985 haya prescrito taxativamente y de forma unificada para el personal funcionario y laboral que la selección habrá de hacerse «de acuerdo con la oferta de empleo público mediante convocatoria públíca y a través del

(30) «El Consultor de los Ayuntamientos y de los Juzgados», El régimen del personal contratado, revista núm. 15, 1979, pág. 1038. 
sistema de concurso-oposición o concurso-oposición libre en los que se garanticen, en todo caso, los principios constitucionales de igualdad, méritos y capacidad, así como el de publicidad" (art. 91.2) (31) redundando para evitar posibles discriminaciones, en el caso del personal laboral, que habrá de salvaguardarse "el máximo respeto al principio de igualdad de oportunidades de cuantos reúnen los requisitos exigidos» (art. 103) (32).

Parece evidente un alineamiento con la nueva legislación estatal en materia de personal y que a falta de un pormenorizado desarrollo reglamentario nos permite incidir en las mismas consideraciones que respecto de aquélla ya hemos hecho.

\section{LA LABORALIZACION DE LA FUNCION PUBLICA Y LA CONSTITUCION DE 1978}

La polémica doctrinal preconstitucional en torno a la concepción jurídica que debe regir las relaciones de empleo en la Administración se asienta sobre bases ideológicas claras, y se polariza, de un lado, en los defensores que desde posiciones progresistas propugnan una "generalización del régimen de empleo laboral y su incorporación a la función pública, considerando de tal modo al funcionario como un trabajador por cuenta ajena más; "laboralizando" la relación funcionarial mediante su homologación con los trabajadores privados" y de otro, en aquellos sectores tradicionales para los que habría que ubicar a los funcionarios públicos dentro de un sistema estatutario que regiría su selección y sus condiciones de trabajo, sin opción a poder alterarlo y con una práctica sumisión a los preceptos reglamentarios (33).

El resultado de esta confrontación política, tras el debate constitucional, se saldará a favor de la segunda posición, si tenemos en

(31) En línea con la reciente legislación de régimen local se ha firmado el Acuerdo sobre oferta de empleo público y promoción interna en las Corporaciones Locales, entre la FEMP y UGT de 25 de junio de 1985 , icuyo punto 1.2 recoge expresamente para el personal laboral la necesidad de que los procedimientos de selección aseguren los principios de mérito y capacidad.

(32) Vicente Gonzalez-Haba: Certamen, núm. 501, enero 1985, pág. 9, mantiene que el legislador rodea la selección en la Administración Local de «unas garantías y condiciones que contrarresten otros factores de todo tipo que tratan de desvirtuarla en aras de presiones políticas, sociales, ideológicas, etc.; y que son más intensas que en la vida de la Administración Centralı.

(33) José Manuel CASTElls se refiere a esta polémica en La Euskadi autónoma y los funcionarios públicos, págs. 91-92. 
cuenta el pronunciamiento de nuestra Constitución en sus artículos 28, 103 y 149.1.18, que vienen a investir al futuro régimen regulador de los funcionarios de connotaciones peculiares, debiendo definirse por vía legal y reglamentaria «las características de la relación de empleo del servidor público, sustrayendo como regla, la determinación de sus condiciones por la vía contractual» (34). Ello supone, en principio, que junto al establecimiento de un régimen específico que conlleva la necesidad de establecer el principio de la inamovilidad de los funcionarios, la proclamación del derecho a la carrera administrativa y un régimen propio de retribuciones e incompatibilidades, existe una negativa a la utilización de las formas reivindicativas características reconocidas en el régimen jurídico laboral. Esta consecuencia inferida por parte de la doctrina administrativista sugiere grandes reservas porque como mantiene PARADA, en nuestra Constitución no hay «una concepción clara sobre la función pública, que nítidamente configure la relación del funcionario con la Administración en términos de relación de Derecho público" (35).

A estos efectos resulta significativo el hecho de que incluso autores que abogan - ante la presencia del interés público que inviste la actividad del personal adscrito a un servicio público- por un sometimiento a reglas especiales de Derecho, excluyendo por tanto el Derecho laboral, se predispongan a una solución de compromiso frente a lo que califican como "creciente tendencia a la desfuncionarización del personal administrativo», propugnando para el funcionario público su ligazón con el Estado en base al establecimiento de «una relación de lealtad sometido a los principios tradicionales de Derecho Público», y en parangón con lo ocurrido en la Administración alemana, la aplicación al personal laboral de reglas jurídicoadministrativas diferentes, admitiendo implícitamente que la regulación laboral pasará a convertirse de regla excepcional en la actualidad a regla general en el futuro (36). Todo induce a pensar que una vez más la realidad antecede al ordenamiento y sólo con mucha lentitud se adaptará a aquélla.

Es en el terreno del sindicalismo funcionarial y del ejercicio del

(34) Santiago MuÑoz MACHADo: «Sobre la burocracia de las Comunidades Autónomas», $D A$, núm. 182, abril-junio 1979, pág. 102.

(35) José Ramón PARADA VÁzoUEz: «Constitución, burocracia y Comunidades Autónomas», DA, núm. 182, abril-junio 1979, pág. 88.

(36) F. Garrido Falla: Comentarios a la Constitución, 2." ed. ampliada, 1985, página 1440 . 
derecho de huelga donde este fenómeno se manifiesta con toda crudeza, y a este respecto cabe recordar los argumentos expuestos por VIDa Soria en el debate en la Comisión de Constitución del Senado, en el que de forma realista opinaba que no se podía ignorar que «la sindicación de los funcionarios públicos, en su aspecto funcional, hoy día está prácticamente equiparada a la sindicación, en su aspecto funcional también, de los trabajadores por cuenta ajena, sin más calificativos" y que el respeto de la esencia de la legislación sindical como es la autonomía de los trabajadores en cuanto interlocutores sociales, debe hacerse de igual forma con los funcionarios públicos y que las restricciones al ejercicio del derecho de huelga por éstos no pueden establecerse a priori por el ordenamiento cons. titucional o por el ordenamiento ordinario, sino "por la propia dinámica, esencia y peculiaridades del movimiento sindical»(37).

Respecto de este último derecho se ha puesto de relieve por EMBID IRUJo el progresivo acercamiento entre las situaciones que afectan al trabajador o funcionario público y al privado, si se tiene en cuenta que "cada vez son más las instituciones de igual funcionamiento para uno y para otro poniéndose el acento en la misión a cumplir y no en el sujeto, público o privado, con el cual tiene lugar la relación de servicio", lo que lleva al citado autor a proponer una asimilación entre el régimen jurídico de la huelga de funcionarios y el de la huelga en los servicios públicos, debiendo conseguirse unà diversificación en función de la misión que cumplen los funcionarios y no por el carácter público que ostentan (38).

(37) Diario de Sesiones del Senado, núm. 45, sesión núm. 7, 29 de agosto de 1978, pág. 1945. Por otra parte, los argumentos tendentes a la restricción del derecho de huelga sobre la base de la no interrupción de los servicios públicos por los funcionarios no puede mantenerse si se tiene en cuenta, como recuerda Antonio Cano Mata: «La huelga de los funcionarios», RAP, núm. 93, 1980, pág. 138, que existe una gran diversidad de servicios imprescindibles prestados por personas privadas y que no por ello están excluidos del derecho de huelga. En esta línea puede consultarse a José María Jiménez CrUZ: aLa huelga de los funcionarios públicos», $D A$, núm. 196, octubre-diciembre, 1982, pág. 50.

(38) Antonio EMBID IRUJo: «La problemática actual de la huelga de funcionarios», $R E D A$, núm. 19, octubre-diciembre 1978, págs. 586-587 y 605-606. Por su parte, E. Borrajo DaCruz opina que ésta es la tendencia hacia la que evoluciona el Derecho comparado en el que el criterio imperante es que ala huelga no se reconoce, autoriza o prohíbe en atención al estatuto jurídico privado o público del trabajador, sino en atención a la naturaleza de la función afectada. Es decir, se reconoce el derecho de huelga tanto a los trabajadores privados como a los funcionarios públicos, y para unos y para otros las restricciones se imponen en beneficio de la comunidad, de modo que se garanticen los servicios mínimos o vitales», añadiendo que ulos servicios atendidos por funcionarios públicos gozan de una fuerte presunción de interés social, pero no son, necesariamente y por sí 
Resulta, pues, excesivo, como expone BELORGEY considerar que todos los funcionarios son igualmente indispensables, en todo moinento y sin ninguna reserva para un funcionamiento regular del aparato del Estado (39) así como predicar de forma maximalista las peculiaridades de la función pública, lo que en realidad suele encubrir un intento de negación de los derechos sindicales de los funcionarios, sin que suponga en modo alguno negar la primacía que el interés general debe ejercer sobre los propios intereses de los funcionarios sindicados (40).

Sin embargo, y a la luz de la legislación preconstitucional vigente en la materia, el Tribunal Constitucional se ha manifestado de forma harto tajante, entendiendo que existe una distinción entre el personal funcionario o asimilado sometido al régimen del Derecho Administrativo y el personal laboral contratado temporalmente, sujeto al régimen correspondiente al ordenamiento jurídico laboral -S. de 27 de julio de 1982 - y que aquél «se gobierna en relación a las condiciones de empleo y trabajo por normas legales y reglamentarias dictadas por los órganos competentes de los diversos servicios públicos, como producto de una relación estatutaria que es reconocida tradicionalmente por la doctrina y la jurisprudencia contenciosa» (41). Las consecuencias de este aserto jurisprudencial

mismos, servicios esenciales o vitales». Vid. «El derecho de huelga de los funcionarios públicosn, $R E D C$, vol. 1, núm. 2, mayo-agosto 1981, pág. 140.

(39) Para G. BELORGEY: Le droit de la grève et les services publics, 1964, pág. 80 , de su análisis puede sugerirse aune seconde conception qui pourrait être à la base d'un texte relatif à la grève dans les services publics. Au nombre des personnels dont le droit de grève serait etroitement réglementé, et auxquels il pourrait même être retiré, seraient placés ceux des fonctionnaires investis d'une mission d'autorité ou exerçant des tâches de sécurité ainsi que ceux des agents des services publics économiques détenteurs de postes de directions actives, ou exerçant des activitésclefs. Tous les autres personnels pourraient recourir à la grève dans les conditions du droit commun, ce droit étant éventuellement assorti de la mise en place de mécanismes institués en vue de la solution pacifique des conflitsn.

(40) Vid. Luis Enrique DE LA VILLA: “La sindicación de los funcionarios públicos», Cuadernos de Derecho del Trabajo, 1975-1976, núms. 1 y 2, pág. 226.

(41) En congruencia con la doctrina sentada por el Tribunal Constitucional y con expresa invocación a la misma, el Tribunal Supremo se ha pronunciado con posterioridad en repetidas Sentencias de 20-4-1983 (R. 2.230), 23-41983 (R. 2.238), 30-6-1983 (R. 3.677), etc. Por tener particular interés, extraemos de la S. de 1-3-1983 (R. 1.357) uno de sus considerandos, en el que se dilucida sobre la infracción de normas legales como consecuencia de la aprobación de un convenio colectivo cuyo ámbito de aplicación alcanza y regula las relaciones entre un Ayuntamiento "y todas las personas que tengan una relación profesional y retribuidan y a estos efectos señala que: «CDO.: Que ningún obstáculo afectaría a la competencia municipal (art. 8. .1 del RD-ley 3/81) para concertar legales condiciones de trabajo mediante negociación colectiva, y tampoco así se aduce por el órgano de la Administración Central recurrente y apelante, si el ámbito de aplicación del Convenio aquí tratado se hubiere reducido a las relaciones del Ayuntamiento con su personal sujeto al 
serán necesariamente la posibilidad de modificación unilateral de tal status por la Administración sin que quepa ostentar por parte de los funcionarios la detentación de un derecho adquirido a su mantenimiento, al mismo tiempo que ven negada validez alguna a posibles convenios con la Administración y tener su nombramiento la condición de acto de autoridad y por tanto no contractual.

La intervención de los funcionarios públicos en la detèrminación de la prestación de servicios o de condiciones de empleo, la entiende el Tribunal Constitucional "como mera participación en sistema de consulta o información, sin vinculación alguna para los poderes públicos, que no alteran ni podían hacerlo el significado y alcance que tiene la regulación de la función pública», al mismo tiempo que niega que del derecho de sindicación que les reconoce la Constitución en su artículo $103.3 .^{\circ}$ se derive como consecuencia necesaria la negociación colectiva, lo que no supone su negación, pero en opinión de SANTAMARía PASTOR «expresa veladamente un prejuicio contrario a la misma» (42).

Derecho Laboral; del propio modo que no existiría aquel obstáculo a su competencia si la Corporación, en uso de la potestad reglamentaria aneja a su autonomía, que no es lo mismo que soberanía - art. 140 de la Constitución - hubiere acogido materias previamente objeto de negociación colectiva en una Ordenanza organizativa del régimen interno de sus servicios a los administrados en desarrollo de, y en todo ajustado a la legalidad vigente dimanante del Estado y disposiciones reglamentarias de su Administración Central en particulares de su propia competencia (arts. 103.3 y 149.18 de la Constitución); pero asignar al Convenio Colectivo la amplitud de aplicación personal transcrita en el primer Considerando de esta Sentencia, constituye evidente transgresión del artículo 1.3.a) del Estatuto de los Trabajadores aprobado por L. 8/1980, de 10 de marzo, a cuyo tenor se excluye de su ámbito la relación de servicios de los funcionarios públicos, así como la del personal al servicio del Estado, las Corporaciones Locales y las Entidades públicas autónomas, cuando al amparo de una Ley, dichas relaciones se regulen por normas administrativas o estatutarias; y como quiera que no sólo a nivel de Ley.... sino que incluso al supremo rango de normas constitucionales (arts. 103.3 y 149.1.18 citados), la regulación de la función pública - salvo ley que la transfiera, que aquí no existe- es competencia del Estado, resulta así manifiesta la transgresión legal referida al aprobar el Ayuntamiento de Sagunto Convenio Colectivo que no distingue entre personal sometido al Derecho Laboral y al Derecho Administrativo para excluir a este último de su ámbito de aplicación...n.

(42) Juan A. Santamarfa Pastor: Comentarios a la Constitución, pág. 572, señala como obstáculos a su reconocimiento la imposibilidad de aplicar a la Administración pública la dialéctica trabajador-empresario y la negativa a admitir que un pacto colectivo entre funcionarios y Gobierno vincule al órgano legislativo a la fijación de las cifras presupuestarias. Para J. M. Castells, op. cit., pág. 92, «el expreso reconocimiento del derecho de sindicación a los funcionarios públicos en la Constitución, desplaza la temática a un terreno de difícil comunicación, puesto que sindicatos y negociación colectiva con los métodos de presión pertinentesi, son inseparables" por lo que aboga, ante lo que entiende como una indefinición de la Constitución al respecto, por una «interpretación amplia, favorable a las libertades públicas y derechos de los ciudadanos». 
En cualquier caso, la referida sentencia deja una puerta abierta a una alteración legislativa futura, estableciendo tan sólo que «de la legislación vigente» se infiere ese tratamiento diferenciado, así como que «en la actualidad la negociación colectiva de las condiciones de trabajo del personal vinculado a cualquiera de las Administraciones Públicas, sólo es posible legalmente cuando se trate de personal sometido al Derecho laboral pero no en cambio, en relación al personal vinculado de Derecho administrativo..., por tener una relación funcionarial sujeta a esta última rama del Derecho, donde no está admitido tal sistema por ausencia de aceptación y regulación y por contradecir el régimen legalmente establecido».

Así pues, la propia Constitución permite afirmar que los criterios de delimitación entre el personal estatutario y el personal laboral se reconducen tras su promulgación al terreno de la norma. Efectivamente, el ordenamiento, como afirma ORTEGA, "contempla la existencia de voluntades e intereses que no son generales, pero que gozan de la tutela de las instituciones públicas» (43) y que simbolizan la voluntad del Estado en cada momento, voluntad cambiante en función de los resultados electorales y frente a la cual habrá que mantener la independencia del funcionario (44). En este sentido, podemos abundar que la Constitución no refiere un tipo de funciones o tareas concretas a desempeñar por los funcionarios que se diferencien de las del personal laboral, lo que permite admitir como válido un sistema de contratación laboral en la Administración que «quizá se adaptara mejor a determinadas funciones que el rígido estatuto del funcionario público» (45), sin que ello suponga negar, a la vista del propio mandato constitucional, la existencia de personas que no pueden regirse por el Derecho del Trabajo.

Estas personas podrían reducirse a aquellas que ejercen su acti-

(43) Vid. Luis ORTEGA: «Reflexiones en torno a una revisión de los planteamientos generales de la relación de empleo públicon, $R E D A$, núm. 26, julio-septiembre 1980, pág. 426 .

(44) En este sentido se pronuncia A. EMBID IRUjo en recensión incluida en la $R E D A$, núm. 23, octubre-diciembre 1979, págs. 663-667, atribuyendo al funcionario el papel de cumplir y poner en marcha el programa político del Gobierno, y defendiendo tanto su independencia como la de la Administración en sí afrente a un Gobierno que lo es en tanto que un partido ha ganado unas determinadas elecciones».

(45) Así se manifestaba Baena del Alcázar en las Primeras Jornadas de la Función Pública, organizadas por FETAP-UGT y recogidas en Tres dias en torno a la Reforma de la Función Pública, 1981, pág. 86. 
vidad como autoridades públicas (46), respecto de las demás, por exclusión, y como consecuencia inmediata del reconocimiento de sus derechos sindicales cabe hablar de relaciones de igualdad con la Administración en cuanto se refiere a la denominada relación de servicio.

Es innegable el deterioro producido en las notas definitorias de la función pública (estabilidad, permanencia...) en progresión paralela a las influencias provenientes del campo laboral, producto, al decir de VÁzQuez DE PRADA de «una reacción envolvente que buscaba globalizar la misma denominación laboral, por sus mismas connotaciones sociales, procurando en una primera etapa la unidad de todas las fuerzas laborales, y en una segunda, generalizar por la vía del número los problemas hasta entonces exclusivos de determinadas partes del sector laboral» (47).

En ausencia del Estatuto de los funcionarios públicos, previsto en el artículo $103.3 .^{\circ}$ de la Constitución, el conjunto de disposiciones reguladoras referidas al personal laboral al servicio de la Administración es extremadamente complejo y creemos que dada su diversidad se justifica ir avanzando en el terreno normativo hacia un tratamiento conjunto de situaciones laborales y funcionariales idénticas. Hay que tener en cuenta que aunque el reconocimiento constitucional del sometimiento del funcionario público a un régimen estatutario significa su separación del status del trabajador por cuenta ajena, no se puede entender la misma de forma absoluta, ya que como afirma SÁNCHEZ MoRón (48), ello no es posible, en atención a la titularidad de unos mismos derechos, al principio de eficacia en la acción administrativa "que tiende a equiparar la organización de los servicios públicos a la de la empresa privada" y sobre todo en aras del principio democrático que obliga a superar la concepción de la sociedad como ente organizativo cerrado a los estímulos sociales y políticos. La consecuencia lógica debe ser una lectura de

(46) En este sentido cabe referirse cuando por ejemplo GaRRIDo Falla habla del obstáculo al derecho de huelga dimanante del acarácter de autoridad de que ciertos funcionarios están investidos», Comentarios..., pág. 1442. No puede omitirse la dificultad inherente a la delimitación conceptual de la autoridad administrativa, expresión que implica diversos sentidos, a los que se refiere LópEz-F. MARQUEz en "La noción de autoridad en la legislación y jurisprudencia penal», RAP, núm. 92, 1980, págs. 368-369.

(47) Vid. Valentín R. VAzquez de PRAda: «El funcionario público: señas de identidad", $D A$, núm. 189, enero-marzo, 1981, pág. 187.

(48) Miguel SANCHEZ MORON: «Notas sobre la función administrativa en la Constitución Española de 1978», incluido en La Constitución Española de 1978, 1980, págs. 649-650. 
la Constitución guiada por un criterio de interpretación no cicatero, que permita un desarrollo no restrictivo de los derechos laborales al conjunto del personal que trabaja en la Administración (49).

Parece, pues, claro que del hecho de que la Constitución establezca principios para garantizar el buen funcionamiento de la Administración, no debe derivarse como apostilla ORTEGA el que obedezcan «a una regulación autoritaria de las relaciones de empleo de los funcionarios públicos", sino que lo que está haciendo en realidad es recoger «una amplia lista de derechos y libertades aplicables a los funcionarios, que abogan por el reconocimiento de la autonomía colectiva funcionarial frente a la Administración" (50).

Si consideramos que el objetivo fundamental a conseguir por cualquier proyecto de reforma de la función pública es dotar al personal al servicio de la Administración de las notas de profesionalidad y de neutralidad frente al poder político y al servicio del administrado, éstas no pueden sufrir menoscabo en función de la distinta naturaleza jurídica que liga al empleado público con la Administración, al menos a priori, sino que su deterioro dependería de factores ajenos a la misma y que serían fácilmente evitables siempre que se establezcan garantías de objetividad tanto respecto del acceso a la Administración como en cuanto al desempeño de las «funciones» a realizar.

No se puede objetar que el ingreso en la Administración de! personal laboral puede realizarse mediante un sistema de contratación pura y simple, y ello ha servido de base para que desde posiciones doctrinales conservadoras se establezcan comparaciones en mayor o menor medida con el denominado spoil system, pero es que existe una segunda posibilidad de acceso y es el establecimiento de modalidades similares al sistema de oposiciones u otros en los

(49) José Luis FUERTES SUAREZ: Función pública, reforma administrativa y $E s$ tado autonómico, 1980, pág. 93, propone incorporar al futuro texto sobre funcionarios públicos varios aspectos de la regulación contenida en el Estatuto de los Trabajadores y a estos efectos se refiere a la aplicación en ciertos casos de la contratación a tiempo parcial, la clarificación de los contratos de duración determinada, las mejoras establecidas en el ámbito laboral en Ordenanzas y convenios, los sistemas de representación y de participación en la dirección y gestión de los centros de trabajo, el régimen regulador del derecho de reunión y sobre todo «la reconsideración que del concepto estatutario (en cuanto definidor del status funcionarial y justificador de modificaciones unilaterales del mismo), entendemos que debe hacerse a la vista del procedimiento rígido de garantías que al respecto establece el Estatuto de los Trabajadores (art. 37 y sigs.)".

(50) Luis ORTEGa: Los derechos sindicales de los funcionarios públicos, 1983 , páginas $46-47$. 
que en todo caso se respete un sistema reglado, salvaguardando los principios constitucionales del mérito y la capacidad (art. 103.3. ${ }^{\circ}$ ).

En cualquier caso, la relación que une al empleado público con la Administración estará condicionada por las dos claves conceptuales que definen a ésta y de la primacía que se otorgue a una u otra: o bien hablamos de Administración de autoridad, y con ella nos referiremos principalmente a una relación de carácter estatutario en la que habrá que considerar los efectos secundarios de absorción de la personalidad jurídica del funcionario como persona física - al menos, en tal aspecto- y de sumisión del mismo al factótum de la relación, como es el Estado o el ente público corres. pondiente (51) o por el contrario, hablaremos de una Administración de gestión y en la medida en que se entiende como ente prestador de servicios habrá que restringir el concepto de funcionario público, sometiendo a su personal a la legislación laboral, lo que no significa que tenga carácter residual, sino que en consonancia con la clase de actividades, o lo que es lo mismo según la naturaleza de los servicios públicos que se presten, habrá que pensar que una gran parte de los funcionarios públicos actuales podrían verse afectados por un marco jurídico laboral (52). Tesis ésta admisible para BAENA, aunque matizando que una parte considerable del personal estará sometido al régimen estatutario, pero permite mantener como opción abierta «la exclusión de este régimen público de ciertos funcionarios", cuestión ésta que debería resolverse mediante Ley del Estado o de las Comunidades Autónomas (53).

El hecho de que la Administración apele al concepto de servicio público o al de interés público, para someter la relación de servicios a un Derecho Público especial, no permite afirmar su inmutabilidad, antes bien, estará sujeta a cambios históricos (54) y más si

(51) Valentín R. VÁzquez de PRADA: El funcionario público..., pág. 207.

(52) Mientras que para VAZquEZ DE PRADA «únicamente sería personal estatutario, sujeto a las correspondientes normas específicas sobre la función pública,..., aquel que fuese seleccionado de acuerdo con dichas normas, quedando, por el contrario, a su margen a los demás colectivos seleccionados por la vía directa del contrato, indirecta del concurso o de nombramiento digital del interino o eventual, que quedaría sujeto a la legislación laboral aunque fuera con alguna particularidad», El funcionario público..., pág. 210.

(53) Vid. Mariano BaENa del AlCázar: «La función pública en la Constitución y en las Leyes Orgánicas", incluido en el Libro homenaje al profesor Mesa Moles, Administración y Constitución, págs. 54-55.

(54) Vid. Mario Rusciano: L'impiego pubblico in Italia, pág. 339, mantiene que ase ciò̀ sono profondamente alterati $\mathrm{i}$ fondamenti tecnici e ideologici che portarono all'istituzione della giurisdizzione esclusiva, appare logico porre parallelamente in discussione, con la normativa sostanziale, tutta l'impalcatura processuale. 
tenemos en cuenta, como hemos afirmado antes, que en muchos casos, la actividad de los funcionarios no puede diferenciarse de la de los trabajadores privados, por lo que a pesar de que no es fácil, como advierte LÓPEZ GANDÍA, habrá que establecer la distinción entre funcionarios identificados de forma inapelable con la Administración y aquellos otros cuyas prestaciones laborales o de servicios no implican actos administrativos formales (55).

Pero no se trata tan sólo de establecer una distinción desde el punto de vista de la naturaleza jurídica que liga al personal con la Administración, esto es, su sometimiento a reglas de Derecho Administrativo o laboral, sino que el modelo de organización que adopte la Administración puede responder a principios diferentes y entonces cabría hablar de sistema abierto frente al sistema cerrado (56), este último actualmente predominante en los países que adoptaron los rasgos esenciales del modelo burocrático francés que gira en torno a la consagración de la estabilidad en el empleo como garantía de una carrera permanente. La introducción de un sistema abierto - la recepción parcial de su influencia supondría trasladar los esquemas mentales y los métodos operativos de las grandes empresas privadas, con un deslinde claro entre el funcionario público y el empleo ocupado por el mismo.

La tendencia igualitaria entre régimen general y régimen laboral ha sido reseñada por Joaquín Leguina para el que, ya con anterioridad a la aprobación de la Ley de Medidas para la Reforma de la Función Pública, proponía una serie de medidas encaminadas a este fin y que en síntesis serían: a) creación de entes que presten servicios al público y a la propia Administración acogidos al régimen laboral general; b) contratación laboral común para ciertos puestos de trabajo con reserva para los funcionarios públicos de aquellos revestidos de imperium, y $c$ ) control jurisdiccional rápido y eficaz sobre las decisiones en materia de sanciones (57).

Pero independientemente del reconocimiento de la situación estatutaria de los funcionarios públicos, se está produciendo una influencia progresiva y ascendente de los principios establecidos por

La quale un tempo consolidava le ragioni di una reale differenziazione fra pubblico impiego e lavoro privato, ma oggi perpetua, quasi per inerzia, motivi di separatezza ormai smentiti dalla realtà, legislativa e sindicale, dell'impiego pubblico".

(55) J. LOPEZ GANDf́a: Las relaciones colectivas en el empleo público..., pág. 420.

(56) A este problema se refiere GaRRIDo Falla en Reformas..., págs. 23-24.

(57) Joaquín LEGUINA: CEUMT, revista municipal, núm. 57, diciembre 1982, página 20 . 
el Derecho del Trabajo a través de la aceptación y consiguiente recepción interna de los Convenios que constituyen la médula del Derecho Internacional en materia de función pública (58) y que están basados en el reconocimiento de la negociación colectiva en este ámbito, así resulta elocuente la reciente ratificación por parte española del Convenio número 154 de la OIT (publicado en el $B O E$ número 269, de 9 de noviembre de 1985) sobre el fomento de la negociación colectiva, que aunque reconoce que la legislación o la práctica nacionales pueden fijar modalidades particulares en la Administración Pública, se establece expresamente en su artículo 2 que aquella expresión "comprende todas las negociaciones que tienen lugar entre un empleador, un grupo de empleadores o varias organizaciones de empleadores, por una parte, y una organización o varias organizaciones de trabajadores, por otra, con el fin de: a) fijar las condiciones de trabajo y empleo, o $b$ ) regular las relaciones entre empleadores y trabajadores, o $c$ ) regular las relaciones entre empleadores o sus organizaciones y una organización o varias organizaciones de trabajadores o lograr todos estos fines a la vez».

Esta participación en el establecimiento de las condiciones de trabajo ya ha encontrado un reconocimiento implícito en el artículo 3.2.b) de la Ley de Medidas, al admitir la negocicaión entre la Administración y la representación sindical de los funcionarios públicos respecto de sus condiciones de empleo.

El establecimiento de relaciones de alteridad entre la Administración y sus funcionarios debe, pues, asentarse sobre la base de la existencia respecto de estos últimos de unos intereses colectivos distintos de los que sustenta la propia Administración en cada mo-

(58) Merece destacar como normas internacionales con especial repercusión en la materia, los Convenios de la OIT núms. 87 de 9 de julio de 1948, sobre libertad sindical y protección del derecho de sindicación; 98 de 1 de julio de 1949, de aplicación de los principios del derecho de sindicación y de negociación colectiva, ratificados ambos por Instrumentos de 13 de abril de 1977, y el 151 sobre la protección del derecho de sindicación y los procedimientos para determinar las condiciones de empleo en la Administrasión Pública, ratificado por Instrumento de 27 de junio de 1978, así como la Resolución núm. 1 de 31 de marzo de 1971, sobre la libertad sindical y los procedimientos para la participación del personal en la determinación de las condiciones de empleo en el servicio público adoptado por la Comisión Paritaria del Servicio Público y las Conclusiones adoptadas por la Conferencia Técnica sobre el Servicio Público en su reunión del 7 al 16 de abril de 1975 y por último la Recomendación núm. 159 sobre los procedimientos para determinar las condiciones de empleo en la Administración Pública (todas estas normas aparecen reproducidas en $D A$, núm. 183, julio-septiembre 1979, págs. 294-314). A las anteriores, habrá que añadir el Pacto Internacional de Derechos Económicos, Sociales y Culturales de 19 de diciembre de 1966, ratificado por España por Instrumento de 13 de abril de 1977. 
mento, y que sólo pueden venir dados por el reconocimiento de los derechos de sindicación y de huelga, obviando una «regulación de la relación de empleo, tradicionalmente confiada a la ley y al reglamento sin espacio alguno para la autonomía colectiva" (59), derechos que por otra parte han de incidir ineludiblemente tanto en la forma como en el contenido de la relación de servicio que les liga con la Administración.

La reciente publicación de la Ley Orgánica de Libertad Sindical de 2 de agosto de 1985 constituye un verdadero aval a la interpretación que venimos manteniendo, ya que como se manifiesta en su exposición de motivos, "pretende posibilitar un desarrollo progresivo y progresista del contenido esencial del derecho de libre sindicación reconocido en la Constitución, dando un tratamiento unificado en un texto legal único que incluya el ejercicio del derecho de sindicación de los funcionarios públicos a que se refiere el artículo 103.3 de la Constitución y sin otros límites que los expresamente introducidos en ella». El legislador va a equiparar a los funcionarios públicos a efectos del reconocimiento de la libertad sindical a los trabajadores privados, equiparación que se traduce en una unificación de los sujetos - art. 1.2. - considerando trabajadores tanto a los que están sujetos por una relación laboral como a los «que lo sean de una relación de carácter administrativo o estatutario al servicio de las Administraciones públicas». La importancia de este precepto deriva del reconocimiento taxativo y sin exclusiones que engloba a todo el personal, cualquiera que sea la naturaleza jurídica de sus relaciones con la Administración, así como de su amplitud, al abarcar no sólo a la Administración Central, sino a la autonómica y local. Por otra parte, la LOLS viene a recoger el principio de alteridad a que hemos hecho referencia, señalando expresamente en la exposición de motivos, respecto del alcance de su ámbito subjetivo, que se está refiriendo a «trabajadores por cuenta ajena, lo sean o no de las Administraciones Públicas», absolutamente coherente con la regulación de la autonomía colectiva en la Administración, si se tiene en cuenta que el artículo $22^{\circ} .2 . d$ ) recoge sin ambages el contenido del ejercicio de la libertad sindical y que en todo caso comprende «el derecho a la negociación colectiva, al ejercicio del derecho de huelga, al planteamiento de conflictos individuales y colectivos y a la presentación de candidaturas para la elección... de los corres-

(59) J. LOPEz Gandía: Las relaciones..., pág. 410. 
pondientes órganos de las Administraciones Públicas, en los términos previstos en las normas correspondientes» y que deberán contemplarse en el proyecto de ley que el Gobierno remitirá al Parlamento en desarrollo de lo previsto por el propio artículo 103.3 de la Constitución (disposición adicional segunda, 2, de la Ley Orgánica de Libertad Sindical).

Este proyecto de ley se encuentra en la actualidad en fase de anteproyecto (60), y deberá enfrentarse con un escollo jurídico de difícil solución, si se tiene en cuenta que nuestra Constitución -artículo 134.1 - otorga al Parlamento la competencia para aprobar los Presupuestos Generales, y la fijación de retribuciones es parte sustancial de los mismos, por lo que la dificultad de englobar en el concepto de negociación colectiva las condiciones salariales resulta obvia. El problema puede afectar al reconocimiento pleno de la autonomía colectiva de los funcionarios, pero el obstáculo legal resulta evidente, para su superación se ha aducido desde la Administración que la solución se encuentra en la propia LOLS, ya que ésta admite dos vías de tratamiento de la negociación colectiva: la negociación y la consulta, previstas en el artículo 6.3.c) como procedimientos para la determinación de las condiciones de trabajo pero, en cualquier caso, la negociación de los salarios quedaría excluida del proceso negociador quedando incardinada en un procedimiento de consultas (ver nota a pie de pág. núm. 42); ello ha servido para que desde fuentes sindicales se interprete como un no reconocimiento del sistema de convenios al transformarse los órganos negociadores en meros órganos de consulta sin vinculación para la Administración que seguiría fijando unilateralmente sus retribuciones.

\section{A MODO DE CONCLUSION}

Resulta lógico inferir de cuanto hemos dicho que es imposible seguir manteniendo una visión reglamentista de la función pública. La Constitución de 1978 ha venido a consagrar en nuestro país un estado de cosas en este terreno que difícilmente puede conciliarse con una concepción de la Administración Pública como sistema

(60) El diario El Pais de 15-11-1985 se hace eco del proceso de consulta con las organizaciones sindicales del contenido de este proyecto y de las reacciones suscitadas por el mismo. 
cerrado en relación a una sociedad que como la española ha evolucionado en las tres últimas décadas a un ritmo que desaconseja por sí mismo incidir en errores pasados. No se trata de argumentar en base a intencionalidades políticas, sino de plantearse cómo llevar mejor a efecto el mandato constitucional de servir con objetividad los intereses generales, y a este respecto, tanto las tendencias evolutivas en el Derecho Internacional como nuestra propia experiencia aconsejan abrir las puertas a principios fuertemente consolidados desde hace mucho tiempo en el ámbito del Derecho del Trabajo. Para ello se hace preciso deslindar los conceptos de relación orgánica y relación de servicio en la función pública de un modo efectivo, y es en el marco de esta última donde resulta admisible trasladar las mejores prácticas de la empresa privada y donde puede justificarse un reconocimiento real de los derechos públicos subjetivos que como ciudadanos les corresponde ostentar a los funcionarios públicos.

Las limitaciones inherentes a la prestación de los servicios públicos y la detentación que de la titularidad del ejercicio de autoridad ostentan determinados funcionarios, en ningún caso resultará un obstáculo para frenar lo que ha dado en llamarse proceso de laboralización, que entendido en el marco de los principios constitucionales de actuación con eficacia y de respeto al mérito y capacidad en el acceso a la función pública puede actuar como factor progresivo de transformación de esta última.

Es en esta dirección en la que cabe incardinar la evolución de nuestro ordenamiento en los últimos años, cuyos jalones fundamentales son la LMRFP y la propia LOLS, que prescindiendo de evidentes defectos de técnica jurídica - especialmente en la primera de ellas- configuran un tratamiento unitario del personal al servicio de la Administración, así como un desarrollo en la legislación interna del contenido de los tratados internacionales en materia del establecimiento de las condiciones de empleo y de los derechos de negociación colectiva, sindicación y huelga.

La diferenciación consagrada entre el personal sometido al régimen administrativo y el contratado en régimen laboral, sólo encuentra su última ratio en la propia tradición legislativa, pero no en fundamentos de índole organizativa que en este caso, las diferentes técnicas aplicables quedan en manos del legislador que puede optar indistintamente por cualquiera de ellas. En este sentido la propia doctrina del Tribunal Constitucional - baste recordar la 
Sentencia de 27 de julio de 1982 - , remite a la regulación legal de cada momento.

Por último habrá que indicar que la conformación de una nueva Administración ligada a la configuración del Estado autonómico ha permitido constatar las insuficiencias derivadas del régimen estatutario de la función pública, por lo que resulta alentador evitar incurrir en los mismos defectos en la construcción de una función pública nueva, sin que ello signifique el no reconocimiento de las garantías de objetividad inherentes al sistema estatutario, pero sin que suponga tampoco permanentizar su excesiva rigidez en otros aspectos. 
REALA-1987, núm. 234. PEREZ MARTINEZ, VALENTIN. EL PERSONAL LABORAL AL SERVICIO ...

REALA-1987, núm. 234. PEREZ MARTINEZ, VALENTIN. EL PERSONAL LABORAL AL SERVICIO ... 